\title{
Análise das concepções de educação ambiental de livros paradidáticos pertencentes ao acervo do Programa Nacional Biblioteca da Escola 2008
}

\author{
Luciana da Silva Caretti ${ }^{1}$ \\ Vânia Gomes Zuin ${ }^{2}$
}

Resumo: O Governo Federal implantou em 1997 um programa de fomento à leitura intitulado Programa Nacional Biblioteca da Escola (PNBE), que encaminha acervos de livros paradidáticos às escolas públicas brasileiras. $\mathrm{O}$ presente artigo procurou traçar uma relação entre esses livros e a educação ambiental (EA) através da análise das obras que abordam questões ambientais pertencentes ao acervo do PNBE 2008. Analisamos três livros e os classificamos de acordo com suas concepções de EA utilizando as categorias que Silva (2007) sugere a respeito das relações que estabelecemos com o ambiente. Utilizamos como metodologia a análise textual discursiva, que transita entre a análise de conteúdo e a análise do discurso. De antemão, podemos afirmar que, embora tenhamos encontrado maior ocorrência da vertente conservadora, os livros apresentam muitas possibilidades para o trabalho com a EA crítica em sala de aula, sendo bons instrumentos para problematizações acerca da temática ambiental e importantes ferramentas no processo de formação de leitores.

Palavras-chave: Concepções de educação ambiental. Livros paradidáticos. PNBE.

1 Pedagoga, mestranda do Programa de Pós-Graduação em Educação da Universidade Federal de São Carlos. Contatos: Rua José Bonifácio, 1375, apart. 34 - Centro - São Carlos - SP - Brasil CEP: 13560-610. E-mail: holaluci@yahoo.com.br

2 Licenciada e bacharel em Química, mestre e doutora em Ciências (Química), doutora em Educação, professora do Depto. de Química e dos Programas de Pós-Graduação em Química e em Educação da Universidade Federal de São Carlos.E-mail:vaniaz@ufscar.br 
Abstract: In 1997 the Brazilian Federal Government implemented a program called National School Library Program (PNBE) aiming to promote reading, by distributing collections of supplementary educational books to public schools. This article sought to establish a connection between these books and environmental education (EE) through the analysis of books from the PNBE 2008 collection that address environmental issues. We analyze three books and classify them according to their conceptions of EE by using the categories that Silva (2007) suggests regarding the relationship we have with the environment. We use the textual discourse analysis methodology, which is in between content analysis and discourse analysis. In advance, we can say that the books provide many opportunities to work with critical EE in classroom, being good instruments for calling environmental themes into question and important tools in reader education process.

Keywords: Conceptions of environmental education. Supplementary educational books. PNBE.

\section{Introdução}

A leitura deve fazer parte do cotidiano escolar.

Começamos nosso trabalho defendendo essa afirmação, pois acreditamos que por meio da leitura entramos em contato com o mundo do outro e a partir dessa experiência geramos importantes ferramentas para a formação de nosso próprio mundo. Zilberman (1990) afirma que a leitura é um processo complexo que serve de veículo para a autoafirmação do indivíduo. Nesse sentido, o/a leitor/a torna-se mais livre para tomar decisões, tecer críticas, definir sua posição, enfim, exercer um papel que o acentue como sujeito.

Muitas crianças só possuem acesso aos livros dentro do ambiente escolar e é também por isso que programas de estímulo à leitura são importantes (WALTY, 2003). Não basta, entretanto, repassar uma série de livros para as escolas sem que haja um estímulo à formação do/a professor/a para o trabalho com esses livros e estratégias de fomento às bibliotecas escolares. O Programa Nacional Biblioteca da Escola (PNBE) foi implantado em 1997 pelo Governo Federal e procura democratizar o acesso aos livros encaminhando anualmente acervos para todas as escolas públicas de educação básica 
do país. Neste trabalho, procuramos traçar uma relação entre os livros paradidáticos e a educação ambiental (EA) através da análise das obras pertencentes ao acervo do PNBE 2008 para o ensino fundamental que abordam questões ambientais. Buscaremos analisá-los e classificá-los de acordo com suas concepções de EA. Para tanto, faremos uso da classificação que Silva (2007) sugere a respeito das múltiplas relações que estabelecemos com o meio ambiente. Marpica (2008) também se utiliza dessa classificação e será, desse modo, referência para nosso trabalho. Faremos a análise de três livros nos quais a temática ambiental está presente.

Os livros paradidáticos são endereçados a um tipo de público caracterizadamente escolar e são tidos como importantes instrumentos no processo de formação de leitores/as. Esses livros se diferenciam dos didáticos principalmente pela forma, pois trazem consigo a intenção de ensinar e divertir (COELHO; SANTANA, 1996, p. 52). Desde a década de 1970, representam grande parcela nas rendas do mercado editorial brasileiro, aumentando gradativamente a cada ano (MELO, 2004, p. 15). Coelho e Santana (1996, p. 59) afirmam que abordar questões ambientais em livros paradidáticos é um caminho promissor para a sensibilização das crianças acerca da problemática que a EA coloca para a sociedade.

A lei 9.795, de 1999, institui a Política Nacional de Educação Ambiental e define que a EA não deve ser uma disciplina curricular na escola, mas deve estar presente de maneira transversal em todos os níveis do processo educativo. Os livros paradidáticos também são importantes no cumprimento dessa determinação da lei, uma vez que, quando abordam a temática ambiental, geralmente o fazem de maneira interdisciplinar.

A valorização da vida, a preocupação com as gerações futuras, o cuidado com o meio e o desenvolvimento de novas formas de pensar a realidade são preocupações da EA que devem estar presentes também na escola. Carvalho (2008, p. 151) coloca que a EA "tem uma proposta ética de longo alcance que pretende reposicionar o ser humano no mundo, convocando-o a reconhecer a alteridade da natureza e a integridade e o direito à existência não utilitária do 
ambiente”. Essas propostas poderiam também estar presentes nos livros paradidáticos, alicerçando esses ideais por meio da leitura.

Para dar continuidade ao nosso trabalho, trataremos agora do PNBE fazendo uma exposição de seu histórico, seus objetivos, seu funcionamento. Depois, abordaremos a classificação proposta por Silva (2007) a respeito das concepções de EA e explicitaremos nossos procedimentos metodológicos para a análise dos livros. Por fim, faremos as considerações finais, ressaltando algumas contribuições para o trabalho educativo com os livros paradidáticos que abordam questões ambientais.

\section{O PNBE}

O PNBE foi criado em 1997 e desde então é executado pelo Fundo Nacional de Desenvolvimento da Educação (FNDE) em conjunto com a Secretaria de Educação Básica (SEB) do Ministério da Educação (MEC). Seus principais objetivos, segundo a apresentação na página do $\mathrm{FNDE}^{3}$, são "a democratização do acesso às fontes de informação; o fomento à leitura e à formação de alunos e professores leitores; e o apoio à atualização e ao desenvolvimento profissional do professor". O programa seleciona e distribui obras de literatura, materiais de pesquisa e de referência e também materiais referentes ao currículo nas várias áreas de conhecimento que compõem a educação básica.

O PNBE tem suas ações executadas de maneira centralizada, contando com o apoio logístico das escolas públicas, das prefeituras e das secretarias estaduais e municipais de Educação. De acordo com informação retirada da página do MEC, todas as escolas de educação básica recebem o acervo do programa. Nos anos pares, são as de educação infantil, anos iniciais do ensino fundamental e educação de jovens e adultos que recebem os acervos. Já nos anos ímpares, as obras são enviadas às escolas dos anos finais do ensino fundamental e do ensino médio.

${ }_{3}$ Disponível em: http://www.fnde.gov.br/index.php/programas-bibliotecada-escola . Acesso em 17/07/2010. 
O edital que torna públicas as normas para a inscrição e avaliação das coleções de literatura, pesquisa, referência e outros materiais referentes ao currículo na educação básica é elaborado pelo FNDE, publicado no Diário Oficial da União (DOU) e disponibilizado também na internet. Nesse edital estão determinadas as regras de aquisição e os prazos para as empresas que possuem os direitos autorais das obras. Segundo o MEC, quem avalia e seleciona as obras do programa é um colegiado instituído anualmente, por meio de portaria ministerial, e composto por representantes do Conselho Nacional de Secretários da Educação (Consed), da União Nacional de Dirigentes Municipais de Educação (Undime) e do Programa Nacional de Incentivo à Leitura (Proler), por intelectuais, técnicos e especialistas na área de leitura, literatura e educação do MEC e por universidades. Já segundo o FNDE, a informação é que as obras do PNBE são avaliadas e selecionadas "por equipes de mestres e doutores de universidades federais, profissionais com múltiplas experiências, entre as quais a docência na educação básica e a formação de professores".

Após a avaliação e seleção das obras por essas equipes, o FNDE negocia com as editoras e adquire os livros por inexigibilidade de licitação - Lei no 8.666/93 -, que tem em vista os direitos autorais das obras. Depois da negociação, firma-se um contrato com as editoras e o FNDE as instrui sobre as quantidades e os locais de entrega dos livros, supervisionando-as integralmente durante o processo de produção das obras. O controle de qualidade dos livros é realizado pelo Instituto de Pesquisas Tecnológicas (IPT), que analisa a adequação de acordo com as normas técnicas da Associação Brasileira de Normas Técnicas (ABNT) e as normas da Organização Internacional de Normalização (ISO) e de manuais de procedimentos de ensaio preelaborados.

Ainda de acordo com o MEC, "dependendo do tipo de acervo e da clientela beneficiária, a distribuição dos livros é feita diretamente das editoras às escolas ou das editoras a um centro de mixagem, para formação das coleções e posterior envio às escolas". Por meio de contrato firmado com a Empresa Brasileira de Correios e Telégrafos (ECT), os livros são distribuídos. Porém, quando se trata de escolas das zonas rurais, as prefeituras e secretarias municipais de Educação é que devem repassar o acervo para as escolas. Toda essa etapa de 
distribuição é acompanhada por técnicos do FNDE e das secretarias estaduais de Educação.

Focamos nossas análises no acervo do PNBE 2008 destinado aos anos iniciais do ensino fundamental. Nesse ano, o programa teve uma abrangência muito grande, pois contemplou, além das escolas de ensino fundamental, as escolas de educação infantil e ensino médio. Os acervos foram compostos por textos em verso, prosa, livros de imagens, histórias em quadrinhos e também os clássicos da literatura universal. De acordo com dados do FNDE, o gasto total com o programa em 2008 ultrapassou 65,2 milhões de reais.

Conforme já colocado, as análises que faremos dos livros do PNBE 2008 serão pautadas pelas categorias utilizadas por Silva (2007), das quais conheceremos um pouco mais no tópico seguinte.

\section{As vertentes de educação ambiental}

Quando falamos em educação ambiental, uma diversidade de concepções e conceituações pode surgir a respeito do que entendemos por EA, do que está "sob o guarda-chuva desta denominação" (CARVALHO, 2004, p. 14). González Gaudiano (2007, p. 03) acentua que:

[...] na educação ambiental têm coexistido aproximações distintas, desde aquelas que colocam ênfase na conservação ecológica até as que têm articulado a problemática da deterioração com o conjunto de condições sociais, econômicas e culturais. Assim, temos visto os mais variados projetos com enfoques próximos ao ensino das ciências naturais e outros vinculados às reivindicações comunitárias.

Percebemos, então, que variadas metodologias, procedimentos, concepções e referenciais orientam as diversas práticas de EA. Carvalho (2004) salienta que não é tarefa fácil se posicionar perante as denominações que categorizam a EA, pois estas não são transparentes ou autoevidentes. A autora defende a abertura de espaços de diálogo entre as diferentes abordagens, de modo que cada uma explicite seus 
pressupostos (CARVALHO, 2004). Muitos/as autores/as têm trabalhado na tentativa de mapear e categorizar as diversas abordagens e práticas de EA, pautando-se pelas concepções existentes de educação, de ambiente, de natureza, de ser humano, da relação ser humano-natureza (CARVALHO, 2004; LAYRARGUES, 2004; SAUVÉ, 2005a; TOZONI-REIS, 2004).

Neste trabalho, para classificar os livros paradidáticos de acordo com suas concepções de EA, utilizaremos a categorização que Silva (2007) sugeriu a respeito das vertentes de EA. A autora propôs três categorias: educação ambiental conservadora, educação ambiental pragmática e educação ambiental crítica.

A educação ambiental conservadora enfatiza a proteção ao mundo natural, do qual o ser humano não faz parte, além de ser tido como destruidor e vilão de uma ordem equilibrada e em harmonia, o que caracteriza uma visão romântica e contemplativa. Há, portanto, uma oposição entre ambiente e ser humano e as questões sociais, políticas e culturais praticamente não são abordadas, pois "são apresentados os problemas ambientais mais aparentes, desprezando-se as causas mais profundas" dos mesmos (SILVA, 2007, p. 59).

A educação ambiental pragmática propõe normas a serem seguidas, pois focaliza suas ações na procura de soluções para os problemas ambientais. Tem como um de seus objetivos a mudança de comportamentos individuais e, segundo Silva, R. (2009), busca mecanismos que permitam a compatibilidade entre o manejo sustentável dos recursos naturais e o desenvolvimento econômico.

A vertente crítica da educação ambiental apresenta a complexidade da relação ser humano-natureza, pautada por questões sociais, políticas, históricas, culturais. Questiona o modelo econômico vigente e "apresenta a necessidade do fortalecimento da sociedade civil na busca coletiva de transformações sociais, a partir de uma práxis transformadora" (SILVA, R., 2009, p. 1174). A educação ambiental crítica valoriza o diálogo como um de seus princípios e está atrelada à educação popular.

Depois de delinearmos brevemente as vertentes que utilizaremos para a categorização de nossos dados, vamos explicitar nossos procedimentos metodológicos. 


\section{Caminhos metodológicos}

Neste artigo iremos analisar e classificar três livros nos quais encontramos a temática ambiental - que em alguns casos é o fio condutor da história, ou seja, os acontecimentos se passam em torno dessa temática. Em outros casos, porém, aparece somente em alguns trechos, o que não impossibilitará nossas análises, uma vez que destacaremos os trechos mais significativos do texto com o objetivo da categorização.

Para nos auxiliar nessa categorização, utilizamos como método a análise textual discursiva, proposta por Moraes (2003) e Moraes e Galiazzi (2006, 2007). Essa abordagem transita entre a análise de conteúdo e a análise do discurso e tem sido cada vez mais utilizada em pesquisas qualitativas. Organiza-se em quatro elementos principais, que Moraes (2003) denomina: desmontagem dos textos, estabelecimento de relações, captação do novo emergente e um processo auto-organizado.

$\mathrm{Na}$ desmontagem dos textos, é feito o processo de unitarização, em que os mesmos são separados em unidades de significado. Nessa etapa se definem e identificam as unidades de análise, objetivando "atingir unidades constituintes, enunciados referentes aos fenômenos estudados” (MORAES, 2003, p. 191). O estabelecimento de relações consiste num processo de articulação dos significados semelhantes, que seria a categorização. Em cada categoria, reúne-se um conjunto de unidades de análise que possuem algum aspecto em comum que as aproxima. Moraes e Galiazzi (2007, p. 73) salientam que a categorização pode se dar a partir de dois processos de naturezas diferentes, um conduzindo às categorias denominadas a priori e o outro produzindo as denominadas categorias emergentes.

O terceiro elemento da análise consiste na comunicação dos sentidos lidos nos textos analisados. Essa comunicação das compreensões é feita por meio da construção de metatextos, que são constituídos, segundo Moraes (2003, p. 202), de "descrição e interpretação, representando o conjunto um modo de compreensão e teorização dos fenômenos investigados", como um esforço para explicitar o que se compreendeu nas etapas anteriores. O quarto elemento - um processo auto-organizado - é a reconstrução teórica 
que parte da análise realizada e "constitui um processo auto-organizado do qual emergem novas compreensões” (MORAES, 2003, p. 192).

Ao tratar da validação, Moraes (2003, p. 199) afirma que "um conjunto de categorias é válido quando é capaz de representar adequadamente as informações categorizadas, atendendo dessa forma aos objetivos da análise, que é de melhorar a compreensão dos fenômenos investigados". O autor ainda destaca que para passar uma imagem mais fiel dos fenômenos que serão descritos é preciso que haja uma boa descrição, com citações dos textos a serem analisados.

Em nosso trabalho, após a escolha dos livros, selecionamos os trechos em que encontramos a temática ambiental e os indícios de possíveis concepções de EA. Destacamos também trechos que possuíam elementos que consideramos capazes de dar mais consistência à temática ambiental, por exemplo, valores como a amizade, o respeito, a cooperação.

Com o corpus composto por três livros, optamos por fazer a correspondência de cada livro com uma letra do alfabeto, que os identificará no decorrer do trabalho ${ }^{4}$. Fragmentamos o texto desses livros em 16 trechos, e cada trecho foi representado por um número. Assim, nosso esquema de fragmentação foi o seguinte:

- Livro A: Catando piolhos, contando histórias - 5 trechos (A1, A2, A3, A4, A5) 5

- Livro B: Você viu meu pai por aí? - 6 trechos (B1, B2, B3, B4, B5, B6)

- Livro C: Barco branco em mar azul - 5 trechos (C1, C2, C3, C4, C5).

Após essa fragmentação, criamos um roteiro para análise, no qual elencamos alguns parâmetros objetivando a classificação dos

${ }^{4}$ Os livros que analisamos são os seguintes: Livro A: COSTA, D. M. Catando piolhos, contando histórias. São Paulo: Brinque-Book, 2006; Livro B: KIEFER, C. Você viu meu pai por aí?. Rio de Janeiro: Civilização Brasileira, 2007; Livro C: ZOTZ, W. Barco branco em mar azul. Florianópolis: Letras Brasileiras, 2005. 17 ed.

${ }^{5}$ Códigos dos trechos correspondentes à fragmentação do texto, em que a letra representa o livro e o número, determinado trecho. 
fragmentos em que encontramos a temática ambiental. Optamos por considerar os fragmentos isolados porque em um mesmo livro pode haver mais de uma concepção, pois, assim como aponta Sauvé (2005a), as tendências não são mutuamente excludentes em todos os aspectos, podendo compartilhar características comuns. Os parâmetros de nosso roteiro foram baseados nos propostos por Carvalho et al. (1996) e Marpica (2008). O item maior que objetivamos analisar é a concepção de EA que os livros veiculam, de modo a classificá-los de acordo com as vertentes descritas anteriormente. Os parâmetros que utilizamos para a criação do roteiro foram os seguintes:

1 - Como entende o ser humano em relação à natureza

2 - Consideração acerca das diversidades sociais, culturais e naturais

3 - Abordagem dos conflitos referentes à temática ambiental

4 - Abordagem da experiência estética e ética com a natureza

5 - Responsabilização pelas causas dos problemas ambientais

6 - Proposta de atuação individual ou coletiva

Tomamos o exposto acima como parâmetros por considerarmos sua abordagem essencial numa perspectiva crítica de EA, que é a que adotamos neste trabalho (CARVALHO, 2004, 2008; GUIMARÃES, 2004; TOZONI-REIS, 2004). Acreditamos que considerar as diversidades sociais, culturais e naturais é imprescindível quando se trata da temática ambiental, uma vez que se torna necessário compreender os tipos de relações sociedade-natureza existentes ou possíveis para que se possa agir sobre determinada realidade. Abordar os valores estéticos e éticos também se faz necessário nessa perspectiva de EA, que tem como um de seus objetivos a formação de "uma atitude ecológica dotada de sensibilidades estéticas, éticas e políticas sensíveis à identificação dos problemas e conflitos que afetam o ambiente em que vivemos" (CARVALHO, 2004, p. 21). De acordo com Carvalho (2006, p. 35), é necessário que os trabalhos educativos se pautem pelos valores referentes à dimensão estética e ética da realidade, "procurando explorar a beleza e os mistérios da natureza, pretensamente desvendados e transformados pela racionalidade cientifica". Para a EA crítica, superar as formas de dominação e as 
relações de poder que hoje se estabelecem é um ideal passível de ser alcançado, não perdendo de vista a complexidade e a totalidade do mundo.

Procuramos organizar cada vertente de EA proposta por Silva (2007) dentro desse roteiro para melhor nos guiarmos no momento da análise dos fragmentos, criando assim nossas unidades de análise. $\mathrm{O}$ Quadro 1 descreve as características de cada corrente de acordo com as tendências de EA para cada parâmetro exposto acima.

Depois de fragmentarmos os textos, categorizamos as unidades de análise, mas as categorias já se encontravam estabelecidas a priori, de acordo com as vertentes propostas por Silva (2007). Moraes (2003, p. 197) salienta que no processo de categorização as categorias podem ser produzidas por diferentes metodologias. Utilizamos aqui o método dedutivo, no qual as categorias já podem existir a partir das teorias que servem de fundamento para a pesquisa e se revelam como o local onde "as unidades de análise serão colocadas ou organizadas". O autor também ressalta a necessidade de que os resultados obtidos no processo de análise sejam comunicados de maneira clara, devendo fazer parte dessa comunicação a descrição do corpus e a interpretação dos resultados obtidos.

A comunicação dos sentidos lidos nos trechos que encontramos foi feita por meio de um metatexto. Em um primeiro momento, optamos por fazer essa comunicação em um quadro. Para identificar cada uma das correntes nesse quadro, vamos indicá-las pelas letras iniciais de seus nomes, apenas por uma questão de otimização de espaço. Assim, as correntes serão identificadas como: conservadora Con; pragmática - Pra; crítica - Cri.

Criamos um quadro para cada livro, no qual constarão os parâmetros que utilizamos para a análise, a vertente predominante em cada parâmetro, um comentário sobre a análise e o código das unidades de análise encontradas no livro que correspondem ao comentário. Logo abaixo dos quadros, passaremos para a quarta etapa de nossa metodologia, na qual tentaremos fazer emergir novas compreensões. Começaremos por analisar o livro A, cujo esquema repetiremos para todos os outros. 


\begin{tabular}{|c|c|c|c|}
\hline & Conservadora & Pragmática & Crítica \\
\hline $\begin{array}{l}1 \text { - Como } \\
\text { entende o ser } \\
\text { humano em } \\
\text { relação à } \\
\text { natureza }\end{array}$ & $\begin{array}{c}\text { Há uma } \\
\text { dicotomia entre } \\
\text { ambiente e ser } \\
\text { humano (visto } \\
\text { apenas como ser } \\
\text { biológico). Visto } \\
\text { como destruidor. }\end{array}$ & $\begin{array}{l}\text { Antropocentris } \\
\text { mo, ser humano } \\
\text { manipula a } \\
\text { natureza, que } \\
\text { reage de acordo } \\
\text { com o trato que } \\
\text { recebe. }\end{array}$ & $\begin{array}{l}\text { Relação complexa, } \\
\text { historicamente } \\
\text { determinada. Ser } \\
\text { humano pertence à } \\
\text { teia de relações e } \\
\text { vive em interação. }\end{array}$ \\
\hline $\begin{array}{l}2 \text { - Consideração } \\
\text { acerca das } \\
\text { diversidades } \\
\text { sociais, culturais } \\
\text { e naturais }\end{array}$ & $\begin{array}{c}\text { Trata apenas da } \\
\text { diversidade } \\
\text { natural. }\end{array}$ & $\begin{array}{l}\text { Não expõe a } \\
\text { diversidade, } \\
\text { pois focaliza as } \\
\text { metrópoles } \\
\text { urbanas e } \\
\text { industriais. }\end{array}$ & $\begin{array}{c}\text { Considera a } \\
\text { diversidade natural, } \\
\text { cultural e social e } \\
\text { suas relações como } \\
\text { um todo. }\end{array}$ \\
\hline $\begin{array}{l}3 \text { - Abordagem } \\
\text { dos conflitos } \\
\text { referentes à } \\
\text { temática } \\
\text { ambiental }\end{array}$ & $\begin{array}{l}\text { Questões que } \\
\text { envolvem } \\
\text { conflitos não são } \\
\text { abordadas. }\end{array}$ & $\begin{array}{l}\text { Apresenta o } \\
\text { conflito como } \\
\text { um "falso } \\
\text { consenso". }\end{array}$ & $\begin{array}{l}\text { Apresenta o conflito } \\
\text { na perspectiva de } \\
\text { vários sujeitos } \\
\text { sociais. }\end{array}$ \\
\hline $\begin{array}{l}4 \text { - Abordagem } \\
\text { da experiência } \\
\text { estética com a } \\
\text { natureza }\end{array}$ & $\begin{array}{l}\text { Experiência } \\
\text { estética plena, } \\
\text { contemplativa. }\end{array}$ & $\begin{array}{c}\text { A abordagem é } \\
\text { utilitarista e não } \\
\text { há experiência } \\
\text { estética. }\end{array}$ & $\begin{array}{c}\text { A experiência } \\
\text { estética é complexa, } \\
\text { pois somos parte da } \\
\text { natureza. }\end{array}$ \\
\hline $\begin{array}{l}5 \text { - Responsabi- } \\
\text { lização pelas } \\
\text { causas dos } \\
\text { problemas } \\
\text { ambientais }\end{array}$ & $\begin{array}{l}\text { Todos são } \\
\text { igualmente } \\
\text { responsáveis. }\end{array}$ & $\begin{array}{l}\text { As causas não } \\
\text { são discutidas. }\end{array}$ & $\begin{array}{l}\text { As causas são } \\
\text { consequên-cias do } \\
\text { contexto histórico e } \\
\text { cultural da } \\
\text { sociedade. }\end{array}$ \\
\hline $\begin{array}{l}6 \text { - Proposta de } \\
\text { atuação } \\
\text { individual ou } \\
\text { coletiva }\end{array}$ & $\begin{array}{l}\text { As ações giram } \\
\text { em torno da } \\
\text { mudança } \\
\text { individual de } \\
\text { modos de vida. }\end{array}$ & $\begin{array}{l}\text { Individual, com } \\
\text { a mudança de } \\
\text { comportamento } \\
\text { de cada um. }\end{array}$ & $\begin{array}{c}\text { Ênfase na } \\
\text { participação } \\
\text { coletiva, } \\
\text { fortalecimento da } \\
\text { sociedade civil. }\end{array}$ \\
\hline
\end{tabular}

Quadro 1: características de cada vertente de EA de acordo com os parâmetros utilizados para a categorização das unidades de análise. 
É importante salientar que, quando determinado livro não abordar o parâmetro em questão, assinalaremos com um traço a célula correspondente na tabela, pois alguns livros podem não tratar de todos os parâmetros.

O livro A (Catando piolhos, contando histórias, de Daniel Monteiro Costa) aborda as memórias da infância de um menino que fala das tradições de seu povo, a tribo Munduruku, transmitidas pela narrativa oral. Enquanto catavam piolhos nas crianças e faziam carinho em suas cabeças, os mais velhos iam contando histórias e mostrando os valores, a tradição, os hábitos e costumes da tribo. Falavam também sobre as formas de relacionamento entre os índios na aldeia e sobre a relação com o ambiente natural. Possui oito relatos que versam sobre mitos, lendas dos espíritos da floresta, memórias das brincadeiras de infância.

Em todo o livro podemos encontrar exemplos de relações muito próximas entre todos os seres da natureza, relações de respeito e de igualdade em que todos são partes de um grande conjunto. Segundo nossas análises, a vertente que predomina nesse livro é a conservadora, embora possamos encontrar exemplos da vertente crítica também. Ressaltamos que se trata de uma história que aborda uma cultura diferente da convencional, isto é, os hábitos e modos de agir e de se relacionar de uma tribo indígena, e a história é contada por um integrante da tribo, ou seja, por quem vivenciou as experiências narradas. Portanto, parte de uma diversidade em relação ao modo historicamente dominante de se estabelecerem as histórias: contadas comumente do ponto de vista do ser humano ocidental, branco, escolarizado. Não há nenhum trecho que aborde claramente a diversidade, mas o livro já parte da diversidade e narra suas histórias com maestria e respeito a todas as formas de vida. Por isso, percebendo-o no contexto geral, verificamos que nesse aspecto a obra A se insere na vertente crítica, que considera as diversidades e percebe também as relações entre elas.

Para uma perspectiva crítica de educação ambiental, é demasiado importante que as formas de se relacionar com a natureza e a cultura não sejam tratadas de maneira hegemônica, que diversas culturas sejam apresentadas e sirvam de reflexão para a busca de uma nova racionalidade (MAULIN, 2009). 


\begin{tabular}{|c|c|c|}
\hline \multicolumn{3}{|c|}{ Livro A - Catando piolhos, contando histórias } \\
\hline Parâmetros & $\begin{array}{l}\text { Tem- } \\
\text { dência }\end{array}$ & Unidade de análise/ comentário \\
\hline $\begin{array}{l}1 \text { - Como entende } \\
\text { o ser humano em } \\
\text { relação à natureza }\end{array}$ & Con & $\begin{array}{l}\text { A2 e A4. No contexto geral do livro verificamos } \\
\text { que ora apresenta uma visão que integra o ser } \\
\text { humano no ambiente natural, ora o exclui. No } \\
\text { entanto, sempre sobressai uma relação de respeito: } \\
\text { !dentro de si tinha um pouco de medo, pois sabia que a } \\
\text { floresta, embora seja nossa amiga e parente, esconde mistérios } \\
\text { e segredos que ainda não conhecemos" e "é preciso estarmos } \\
\text { atentos aos sinais da natureza, ela nos revela quem somos e } \\
\text { qual o melhor caminho a seguir". }\end{array}$ \\
\hline $\begin{array}{l}2 \text { - Consideração } \\
\text { acerca das } \\
\text { diversidades } \\
\text { sociais, culturais e } \\
\text { naturais }\end{array}$ & Cri & $\begin{array}{l}\text { O livro retrata a cultura e os hábitos de uma tribo } \\
\text { indígena e, portanto, leva em conta a diversidade. } \\
\text { Não relaciona essa cultura com outra, mas convida } \\
\text { o leitor para refletir sobre as diferenças. Na } \\
\text { perspectiva crítica, é demasiado importante que as } \\
\text { formas de se relacionar com a natureza e a cultura } \\
\text { não sejam tratadas de maneira hegemônica. }\end{array}$ \\
\hline $\begin{array}{l}3 \text { - Abordagem } \\
\text { dos conflitos } \\
\text { referentes à } \\
\text { temática ambiental }\end{array}$ & Con & $\begin{array}{l}\text { Não menciona diretamente os conflitos, mas estes } \\
\text { geralmente são resolvidos por meio das divindades, } \\
\text { dos espíritos da floresta. }\end{array}$ \\
\hline $\begin{array}{l}4 \text { - Abordagem da } \\
\text { experiência } \\
\text { estética com a } \\
\text { natureza }\end{array}$ & Con & $\begin{array}{l}\text { A1. Aborda elementos estéticos como uma } \\
\text { experiência plena, contemplando a interação do ser } \\
\text { humano com o ambiente natural: "sempre que chegava } \\
\text { em casa (...) minha mãe mandava que eu fosse ao igarapé } \\
\text { para tomar um gostoso banho (...). Apenas nos preparava } \\
\text { para a noite que vinha. (...) 'a noite é como um véu que } \\
\text { cobre a gente de beleza e felicidade?". }\end{array}$ \\
\hline $\begin{array}{l}5 \text { - Responsabili- } \\
\text { zação pelas causas } \\
\text { dos problemas } \\
\text { ambientais }\end{array}$ & - & O livro não faz menção aos problemas ambientais. \\
\hline $\begin{array}{l}6 \text { - Proposta de } \\
\text { atuação individual } \\
\text { ou coletiva }\end{array}$ & Con & $\begin{array}{l}\text { A3 e A5. Atuação individual e coletiva: "quem vive } \\
\text { numa aldeia sabe que todos são responsáveis por tudo"; "é } \\
\text { importante que todos façam a sua parte, para que nosso } \\
\text { mundo continue vivo e alegre". }\end{array}$ \\
\hline
\end{tabular}

Quadro 2: Parâmetros utilizados para a análise, a vertente predominante e as unidades de análise correspondentes do livro A. 
Quando tratamos de questões referentes à proposta de atuação individual ou coletiva, acreditamos que os dois tipos de atuação são necessários. Segundo Carvalho (2004, p. 19):

[...] para a educação ambiental crítica, a prática educativa é a formação do sujeito humano enquanto ser individual e social, historicamente situado. [...]. Desta forma, recusa tanto a crença individualista de que mudança social se dá pela soma das mudanças individuais: quando cada um fizer a sua parte ${ }^{6}$. Mas recusa também a contrapartida desta dicotomia que subsume a subjetividade num sistema social genérico e despersonalizado que deve mudar primeiro para depois dar lugar às transformações no mundo da vida dos grupos e pessoas [...].

Como exemplo de coletividade, temos o seguinte trecho: "Quem vive numa aldeia sabe que todos são responsáveis por tudo. Ninguém está isento de contribuir para que todos vivam bem e sejam o mais felizes possível. É uma forma encontrada para que ninguém se arvore o direito de achar-se melhor que o outro e quebre, por isso, a harmonia" (COSTA, 2006, p. 10). Também encontramos a valorização da participação individual: "Muitas vezes é preciso que algumas pessoas se sacrifiquem para o bem de todos. É importante que todos façam a sua parte, para que nosso mundo continue vivo e alegre" (COSTA, 2006, p. 14). O livro, de acordo com nossas análises, ora se aproxima mais da vertente conservadora, ora oferece exemplos mais característicos da vertente crítica, oscilando um pouco entre as concepções. Entretanto, pelo contexto geral, notamos que, embora ofereça exemplos de coletividade, baseia-se mais "na parte de cada um", não agregando uma perspectiva de transformação social como fortalecimento da própria comunidade em interação com o mundo. Nesse sentido, no parâmetro de participação, o livro se insere na vertente conservadora, na qual as ações giram em torno da mudança individual das maneiras de se relacionar para o bem estar de cada pessoa (MARPICA, 2008).

${ }^{6}$ Grifos da autora. 
No livro A, podemos encontrar a descrição das atividades dos homens e das mulheres dentro da aldeia. Afirma que é papel das mulheres cuidar dos afazeres domésticos e, nesse momento da história, em que todos estavam sentados ao redor do fogo aceso no centro da casa para contar o que haviam feito durante o dia, ressalta a o lugar da mulher nessa atividade: "Também mamãe ouvia atentamente, embora estivesse envolvida com os afazeres domésticos, sempre acompanhada por nossas irmãs. Todas elas sabiam que deve-riam assim proceder para manter a harmonia de nosso lar" (COSTA, 2006, p. 8). Aos homens cabe o seguinte papel: "Numa aldeia, é papel do homem educar o menino nas artes da caça e da pesca. É papel dele ensinar coisas práticas, que ajudarão os meninos a se tornarem úteis para a sociedade e para sua família" (COSTA, 2006, p. 32).

A princípio, parece haver uma relação de poder do homem sobre a mulher nos trechos citados acima, o que não deve existir numa perspectiva de educação ambiental crítica, que adota o não sexismo como um dos aspectos para "a busca de um novo paradigma ou de um outro jeito de ser para lograrmos viver e sobreviver, enquanto espécie humana, neste pequeno planeta" (VIEZZER, 1995, p. 70). No entanto, no decorrer do livro percebemos que tanto o homem quanto a mulher possuem igual valor, embora sejam marcados por atribuições diferentes. Também é salientada a importância das crianças e dos idosos na vida em comunidade. Viezzer, Rodrigues e Moreira (1996, p. 148) indicam que, para se evitar o sexismo, faz-se necessário "mostrar situações em que o poder e a liderança estejam distribuídos por personagens de ambos os sexos, em que tanto homens quanto mulheres se revezem nos atos heróicos, nas atitudes de defesa e relações positivas com a natureza".

De acordo com nossas análises, o livro em questão é um bom instrumento para se trabalharem as relações do ser humano com o ambiente natural e entre si, refletindo-se sobre as diferenças nessas relações e sobre as formas como a nossa sociedade tem se relacionado. Mesmo não havendo o predomínio da vertente crítica, que é a que defendemos como mais apropriada para o trabalho educativo, é possível que a partir das relações estabelecidas entre os personagens do livro o leitor possa refletir sobre seus próprios conceitos, sobre suas 
próprias formas (e as de sua sociedade) de se relacionar com os outros seres, ocasionando, até, a revisão de alguns valores.

O livro B (Você viu meu pai por aí?, de Charles Kiefer) conta a história de um menino indígena chamado José, que mora em uma tribo nas terras de uma reserva. Seu pai, o cacique Gabriel, é um homem bastante respeitado pelos habitantes da tribo e, de vez em quando, vai até a cidade de Pau-d'Arco para vender seus cestos de taquara e defender os interesses dos índios, pois, entre outros assun-tos, as terras da reserva estão em jogo num processo judicial. Em uma dessas idas, o cacique Gabriel acaba ficando alguns dias na cidade, o que gera preocupação em toda a família de José, principalmente em sua mãe. $O$ menino, então, vai até Pau-d'Arco à procura do pai e passa por diversas situações que sempre explicitam questões bastante recorrentes na sociedade, como o preconceito e a marginalização do índio. Há um conflito socioambiental instaurado, pois as terras da reserva estão sendo disputadas pelos índios e pelos brancos, que, segundo o narrador (o menino José), as querem para plantar soja.

No livro, de acordo com nossas análises, verificamos a predominância da vertente crítica. Nele, são abordadas questões bastante complexas que permeiam o cotidiano de tribos indígenas por todo nosso país, como a problemática da terra, a relação com o homem "branco", com o governo, a justiça. De acordo com Sauvé (2005a, p. 30), a vertente crítica "insiste, essencialmente, na análise das dinâmicas sociais que se encontram na base das realidades e problemáticas ambientais". Logo no início da história, José - o narrador - contextualiza as brigas pelas terras da reserva:

Então, vieram os brancos. Eles trouxeram as cercas, as espingardas, as rezas, as roupas, a cachaça e as doenças. Meu avô diz que os índios morreram como as tanajuras e as borboletas. Morreram tantos que não dá pra contar. Agora, somos poucos, o número de aldeias cabe nos dedos da mão direita. O último lugar que temos para morar é a Reserva. Por isso meu pai briga tanto, faz reuniões, compra armas e pólvora. E é por isso também que os brancos ameaçam ele: porque as terras da Reserva são boas para plantar soja. Os brancos só querem plantar soja, soja e mais soja (KIEFER, 2007, p. 08). 


\begin{tabular}{|c|c|c|}
\hline \multicolumn{3}{|c|}{ Livro B - Você viu meu pai por aí? } \\
\hline Parâr & $\begin{array}{c}\text { ten- } \\
\text { dência }\end{array}$ & Unidade de análise/ comentário \\
\hline $\begin{array}{l}1 \text { - Como } \\
\text { entende o ser } \\
\text { humano em } \\
\text { relação à } \\
\text { natureza }\end{array}$ & Cri & $\begin{array}{l}\text { B1. Não aborda diretamente a relação, mas entende } \\
\text { que é complexa e historicamente determinada: "essa } \\
\text { briga pelas terras da Reserva é muito antiga (...). Nossa } \\
\text { briga então era com os guaranis. Mas não por causa das } \\
\text { terras, porque elas não tinham donos, eram de todos". }\end{array}$ \\
\hline $\begin{array}{l}2 \text { - } \\
\text { Consideração } \\
\text { acerca das } \\
\text { diversidades } \\
\text { sociais, culturais } \\
\text { e naturais }\end{array}$ & Cri & $\begin{array}{l}\text { B3. Considera principalmente a diversidade de } \\
\text { costumes entre índios e "brancos", fazendo uma } \\
\text { crítica ao estabelecimento de estereótipos, à } \\
\text { aculturação e à perda de identidade: "Nós nem somos } \\
\text { mais indios, perdemos nossos costumes e vamos acabar } \\
\text { perdendo as nossas terras". }\end{array}$ \\
\hline $\begin{array}{l}\text { nnflitos } \\
\text { ntes à } \\
\text { ica }\end{array}$ & Cri & $\begin{array}{l}\text { A história gira em torno de um conflito por terras } \\
\text { numa reserva indígena, cuja posse os "brancos" } \\
\text { querem porque as terras são boas para plantar soja. }\end{array}$ \\
\hline $\begin{array}{l}4 \text { - Abordagem } \\
\text { da experiência } \\
\text { estética com a } \\
\text { natureza }\end{array}$ & Cri & $\begin{array}{l}\text { B4. Não aborda muito a experiência estética, mas há } \\
\text { um trecho em que o menino observa uma favela: } \\
\text { "as casas bonitas da cidade tinham desaparecido. O que eu } \\
\text { via agora eram casebres muito pobres, de pedaços de caixotes, } \\
\text { latas de az̧eite e sacos plásticos de adubo". O trecho nos } \\
\text { dá a dimensão da presença do homem e de suas } \\
\text { transformações. }\end{array}$ \\
\hline $\begin{array}{l}5 \text { - } \\
\text { Responsabilizaç } \\
\text { ão pelas causas } \\
\text { dos problemas } \\
\text { ambientais }\end{array}$ & Con & $\begin{array}{l}\text { B2. Embora faça uma crítica a conflitos reais e } \\
\text { recorrentes na sociedade, como a posse de terras, e } \\
\text { aborde a desigualdade na resolução desses conflitos, } \\
\text { generaliza a responsabilidade das causas como } \\
\text { frutos da ambição de todos os "brancos". }\end{array}$ \\
\hline $\begin{array}{l}6 \text { - Proposta de } \\
\text { atuação } \\
\text { individual ou } \\
\text { coletiva }\end{array}$ & Cri & $\begin{array}{l}\text { B6. Os índios sabiam que teriam que se unir para } \\
\text { tentar ganhar a causa da posse das terras e faziam } \\
\text { reuniões, refletiam em conjunto. E no fim da } \\
\text { história, quando fica sabendo que perderam as } \\
\text { terras, o menino José fala para seu pai: "A gente não } \\
\text { pode parar de lutar, não é, par?" O pai responde: "Não, } \\
\text { José, a gente não pode parar de lutar". }\end{array}$ \\
\hline
\end{tabular}

Quadro 3: Parâmetros utilizados para a análise, a vertente predominante e as unidades de análise correspondentes do livro B. 
Essa contextualização coloca o leitor a par dos motivos dos conflitos entre os índios e os brancos. Acreditamos que ela atua também como uma denúncia, pois evidencia as relações de poder às quais os índios são submetidos há tempos. Podemos encontrar outro exemplo que explicita a dominação de um grupo mais poderoso sobre outro no seguinte trecho

O padre ajuda o meu pai nas reuniões com os índios. Foi ele que convenceu a tribo a parar a luta contra os brancos. Ele falou que, se a gente continuasse a guerra, eles iam nos massacrar. Meu pai pensou, pensou, falou com os mais velhos da aldeia, e deu razão ao padre: os brancos eram em maior número e tinham mais espingardas e pólvora (KIEFER, 2007, p. 15).

Sauvé (2005a) salienta que a vertente crítica pretende identificar e denunciar as relações de poder e perceber como a relação com o ambiente se submete ao jogo dos valores dominantes. Nesse sentido, gostaríamos de destacar um trecho em que encontramos uma crítica velada ao processo de aculturação ao qual os índios foram e ainda são submetidos, a começar pela presença da igreja católica, que desde os tempos dos jesuítas marcam a vida das tribos indígenas. José diz: "O sol foi descendo atrás das nuvens, elas pareciam pegar fogo, o céu ficou riscado de fios de luz. Rezei uma Ave-Maria, como o padre Carlos me ensinou, que é a oração dessa hora, quando o dia foge da noite" (KIEFER, 2007, p. 39). A aculturação é um processo que resulta do contato entre culturas diferentes e tem como produto uma mudança aculturativa, ou seja, a incorporação, muitas vezes de forma violenta, de traços e valores de uma cultura por outra (OLIVEIRA JÚNIOR, 2003). No caso indígena, essa aculturação se deu de maneira imposta pela dominação do homem branco europeu.

Outros trechos também marcam a inferioridade e os estereótipos aos quais os índios são submetidos. Quando José está na cidade, um menino o encontra e diz que ele tem cara de índio. Ele confirma dizendo: "Sou, sou índio. Nasci na Reserva do Inhacorá. Meu pai é índio, minha mãe é índia, meus irmãos são índios". Ao que o menino responde: "Ah, então tu é um índio fajuto... [...] Índio de 
verdade anda pelado, peladinho da silva". José ficou indignado com a surpresa do menino, pois estava vestindo camiseta branca e calça de brim, comuns para os índios da reserva. Pensou: "Ah, esse guri é louco! Então índio não ia ter vergonha de sair por aí balançando as partes como boi ou cavalo?" (KIEFER, 2007, p. 17). Em outro trecho, José lembra as palavras de seu pai, o cacique Gabriel, que sempre dizia nas reuniões da comunidade: "Nós nem somos mais índios, perdemos os nossos costumes e vamos acabar perdendo as nossas terras" (KIEFER, 2007, p. 39). Em nosso entendimento, o autor fez uma crítica pertinente ao processo de aculturação imposto aos índios de uma maneira coerente à fluência da história.

Há um trecho do livro que trata do conflito pelas terras no qual o narrador alega que aos brancos somente interessa o plantio de soja: "Branco não pode ver árvore, vai logo derrubando; não pode ver bicho, vai logo matando. Se os brancos pudessem, eles cobriam o mundo inteirinho de soja, não deixavam lugar pruma canjarana, grápia ou ipê-roxo" (KIEFER, 2007, p. 10). Acreditamos que há uma generalização do conflito como se todos os brancos fossem a favor dos latifúndios, da posse desmedida das terras, da destruição das florestas. Numa perspectiva crítica de educação ambiental, seria interessante que os conflitos fossem apresentados partindo da visão de todos os envolvidos na problemática. Embora a narrativa faça uma crítica a conflitos reais e recorrentes na sociedade e aborde a desigualdade na resolução desses conflitos, generaliza a responsabilidade das causas como fruto da ambição de todos os "brancos". Nesse sentido, averiguamos que o trecho assume uma postura conservadora, pois atribui a todo ser humano "branco" a responsabilidade pelos problemas ambientais, como se todos fossem destruidores e malvados (SILVA, 2007, p. 59).

Em determinado trecho do livro aparece a questão da legislação ambiental e, segundo Carvalho et al. (1996, p. 106), essa aparição não é muito constante, exceto em materiais específicos para esse fim. No livro B, o menino José, que é o narrador, conta que o padre Carlos ajuda seu pai nas reuniões com os índios e que "foi ele que convenceu a tribo a parar a luta contra os brancos. Ele falou que, se a gente continuasse a guerra, eles iam nos massacrar" (KIEFER, 2007, p. 15). Por conta disso, o padre deu o seguinte conselho à tribo: "Lutem na 
Justiça, para isso existe a Lei" (KIEFER, 2007, p. 15). Ao final da história, o pai do menino diz: "Passei no escritório do advogado e ele falou que os colonos ganharam a questão porque eles têm escritura. Entrei no primeiro bar e comecei a beber. Como é que eu ia voltar pra Reserva e dizer: 'as nossas terras não são mais nossas?"' (KIEFER, 2007, p. 42). Carvalho et al. (1996, p. 106) salientam que, geralmente, os materiais apenas se referem à questão da legislação, "sem, entretanto, discuti-la". Nesse aspecto, o autor do livro perdeu uma boa oportunidade de abordar essa temática de maneira mais profunda e contextualizada, indo ao encontro dos preceitos da vertente crítica da educação ambiental.

Percebemos que no livro a relação ser humano-natureza é colocada de maneira crítica, sendo complexa e permeada de conflitos. Salientamos que por meio das análises verificamos que ele apresenta uma temática pertinente e atual, sem romantizar o assunto, inclusive com um desfecho condizente à realidade da questão agrária no país.

Já o livro C (Barco branco em mar ąul, de Werner Zotz) narra as aventuras de Geraldinho, um menino que vive em uma aldeia de pescadores que é surpreendida com a chegada de um grande barco, conduzido por um senhor misterioso que conversa com o barco e com uma gaivota, seus únicos companheiros. Todos ficam curiosos para saber quem é o tal senhor e pensam que o barco é assombrado, pois o escutam conversar e não enxergam qualquer pessoa com ele. Só Geraldinho se encoraja a ir conhecer o velho senhor que, ao perceber a aproximação do menino, o chama para subir no barco e, assim, começam uma amizade. Eles passam a se ver constantemente e o velho, que se chama Tomás, vai contando muitas histórias para o menino, com o objetivo de ensiná-lo a não ter maldade no coração.

De acordo com nossas análises, nesse livro a vertente que predominou foi a conservadora, que se origina de um ideário romântico, "onde os vínculos afetivos proporcionados pela experiência de integração da natureza trariam bem[-]estar e equilíbrio emocional, bem como a valorização e proteção do ambiente natural" (SILVA, 2007. p. 59). 


\begin{tabular}{|c|c|c|}
\hline \multicolumn{3}{|c|}{ Livro C - Barco branco em mar azul } \\
\hline Parâmetros & $\begin{array}{l}\text { Ten- } \\
\text { dência }\end{array}$ & Unidade de análise/ comentário \\
\hline $\begin{array}{l}1 \text { - Como entende o } \\
\text { ser humano em } \\
\text { relação à natureza }\end{array}$ & Con & $\begin{array}{l}\text { C3. Relaciona o ser humano à natureza de } \\
\text { maneira romântica, idílica. Coloca que, para se } \\
\text { entender bem com os seres da natureza, basta } \\
\text { ficar amigo deles. }\end{array}$ \\
\hline $\begin{array}{l}2 \text { - Consideração } \\
\text { acerca das } \\
\text { diversidades sociais, } \\
\text { culturais e naturais }\end{array}$ & - & Não aborda a diversidade. \\
\hline $\begin{array}{l}3 \text { - Abordagem dos } \\
\text { conflitos referentes à } \\
\text { temática ambiental }\end{array}$ & Con & $\begin{array}{l}\text { Os causadores dos conflitos são os seres } \\
\text { humanos. }\end{array}$ \\
\hline $\begin{array}{l}4 \text { - Abordagem da } \\
\text { experiência estética } \\
\text { com a natureza }\end{array}$ & Con & $\begin{array}{l}\text { C4. Privilegia bastante a experiência estética: "e } \\
\text { desde então a gente tem passeado pelo mundo, vendo os } \\
\text { passarinhos cantarem para a vida, vendo o mar brincar } \\
\text { nas praias, sempre o vento batendo no rosto da gente e } \\
\text { empurrando o Sonho Azul pra tudo que é lugar". }\end{array}$ \\
\hline $\begin{array}{l}5 \text { - Responsabilização } \\
\text { pelas causas dos } \\
\text { problemas ambientais }\end{array}$ & Con & $\begin{array}{l}\text { C2. Responsabiliza alguns seres humanos pelas } \\
\text { causas: "um dia chegou lá um homem malvado - } \\
\text { quase todas as histórias tem um homem malvado - com } \\
\text { espingarda debaixo do braço, dando tiro pra tudo que é } \\
\text { lado". }\end{array}$ \\
\hline $\begin{array}{l}6 \text { - Proposta de } \\
\text { atuação individual ou } \\
\text { coletiva }\end{array}$ & Con & $\begin{array}{l}\text { Não aborda a questão da participação, fica no } \\
\text { plano da experiência sensível com a natureza, e } \\
\text { é a partir dessa experiência que se pode mudar } \\
\text { individualmente, adquirindo bondade no } \\
\text { coração. }\end{array}$ \\
\hline
\end{tabular}

Quadro 4: Parâmetros utilizados para a análise, a vertente predominante e as unidades de análise correspondentes do livro C.

Verificamos que essa visão idílica, de harmonia, permeia toda a história do livro, assim como no trecho em que a gaivota Clarisse é presa em um viveiro por um homem malvado, bandido sem alma, e consegue escapar e ter a liberdade de volta, redescobrindo um mundo em que "não havia fome, que se houvesse, bastava mergulhar na água e pescar um peixe ou ainda procurar alguma frutinha de mato, que muito 
de comer havia sido espalhado pela mão de Deus. Havia alegria e havia liberdade. E não havia a lei do mais forte, que todos eram iguais" (ZOTZ, 2005, p. 30).

Em um outro trecho o narrador, refletindo sobre seus modos de vida, afirma que não temos de nos preocupar muito com o que vai acontecer amanhã, que devemos ser como os passarinhos: "Olha só os passarinhos. Não se preocupam nem um tico assim, porque sabem que a vida deve ser vivida com alegria. E nunca falta nada pra eles, que tem quem cuida deles" (ZOTZ, 2005, p. 45). Nós, entretanto, não somos passarinhos e estamos inseridos numa rede de relações sociais, culturais, políticas, econômicas que regem nossas condições de vida, o que não significa que devemos aceitar essas condições.

No que concerne à experiência estética com a natureza, averiguamos que o livro também pode ser categorizado na vertente conservadora, pois confere bastante valor a essa experiência. Narra muitos episódios nos quais podemos notar a imersão dos personagens no ambiente natural, sempre valorizando essa vivência: " $E$ desde então a gente tem passeado pelo mundo, vendo os passarinhos cantarem para a vida, vendo o mar brincar nas praias, sempre o vento batendo no rosto da gente e empurrando o Sonho Azul pra tudo que é lugar" (ZOTZ, 2005, p. 51). O livro não aborda a questão da participação política, permanecendo no plano da experiência sensível com a natureza, uma vez que é a partir dessa experiência que se pode mudar individualmente, adquirindo bondade no coração. Loureiro (2004, p. 80) ressalta que:

[...] o importante para esta vertente [conservadora] não é pensar processos educativos que associem a mudança pessoal à mudança societária como pólos indissociáveis na requalificação de nossa inserção na natureza e na dialetização entre subjetividade e objetividade; mas sim pensar a transcendência integradora, a transformação da pessoa pela ampliação da consciência que rebate nas condições objetivas, como caminho único para se obter a união com a natureza e para reencontrar uma essência pura que ficou perdida em nossa objetivação na história. 
Existem alguns trechos que nos dão indícios de que o ser humano é o responsável pelos problemas com a natureza simplesmente por ser ruim: "[...] Daí, um dia, chegou lá um homem malvado - quase todas as histórias t $\mathrm{t}$ ê] $\mathrm{m}$ um homem malvado - com espingarda debaixo do braço, dando tiro pra tudo que é lado, e em tudo que é vida" (ZOTZ, 2005, p. 51). Na educação ambiental conservadora, "ocorre uma relação dicotômica entre o ser humano e o ambiente, onde o primeiro é apresentado como destruidor" (SILVA, 2007, p. 59).

Gostaríamos de ressaltar que o livro C apresenta a dimensão de valores também quando aborda e valoriza sentimentos e atitudes de amizade, de lealdade, de cooperação, de respeito a todas as formas de vida. Bonotto e Semprebone (2010) salientam a importância e a necessidade do trabalho com valores, principalmente quando lidamos com determinadas temáticas, como a ambiental. Entendemos que a abordagem e a valorização desses aspectos são muito importantes para um trabalho de sensibilização em busca de uma racionalidade que não seja pautada pelo individualismo, mas pela coletividade, assim como pretende a vertente crítica da educação ambiental (CARVALHO, 2008).

\section{Considerações finais}

De acordo com as análises que realizamos dos livros paradidáticos do PNBE 2008, verificamos que a maioria deles apresenta muitas possibilidades para o trabalho com a EA crítica em sala de aula, podendo ser considerados instrumentos com potencial para problematizações acerca da temática ambiental e para o processo de formação de leitores/as. Neste trabalho, analisamos três livros e as vertentes de EA que identificamos foram a conservadora e a crítica, com predomínio da primeira. Com exceção do livro C, os outros apresentaram mais de uma vertente em suas análises, demonstrando a diversidade de proposições que pode existir em um mesmo material. Sauvé (2005b, p. 319) nos lembra que é perante um "conjunto de dimensões entrelaçadas e complementares que a relação com o meio ambiente se desenvolve. Uma educação ambiental limitada a uma ou 
outra dessas dimensões fica incompleta e alimenta uma visão enviesada do que seja 'estar-no-mundo"'.

As histórias abordam com frequência a dimensão afetiva dos personagens, das relações que estabelecem entre si e com os outros elementos da natureza. Valores como a amizade, a solidariedade e a lealdade são trabalhados de forma a sensibilizar o leitor para essas questões. Não encontramos nos livros analisados a vertente pragmática, tampouco um caráter normativo, que "se propõe a ditar normas e regras de ação para aquele que se quer atingir (...) regras de como se comportar diante da natureza", geralmente encontrado em muitos materiais que se propõem a abordar a temática ambiental (CARVALHO. et al, 1996, p. 103). A presença de valores éticos nas histórias não teve o objetivo de prescrever ou impor normas, mas de sensibilizar para as questões referentes à relação com a natureza, incitando a reflexão sobre as atitudes que são tomadas. Ainda segundo Carvalho et al. (1996, p. 103), "ao normatizar o comportamento do homem diante da natureza, [o livro] assume um tom imperativo, isto é, anuncia o que deve e o que não deve ser feito com relação à natureza, de forma categórica".

Entendemos que uma problemática, sempre que abordada, deve ser discutida levando-se em consideração as perspectivas de todos os envolvidos nela, assim como prevê a corrente crítica de EA, para podermos, assim, compreender as realidades e o contexto no qual se insere. Pensamos que os livros poderiam enfatizar com maior profundidade esses aspectos, uma vez que verificamos que, em geral, a história é contada somente pelo lado do personagem principal. Sabemos dos limites que o tipo de material analisado carrega quanto à sua forma e finalidade, mas acreditamos que a abordagem dessas questões de maneira mais critica e até mesmo democrática favoreceria o/a leitor/a em sua leitura do mundo, realizada por meio do contato com o livro paradidático.

Nesse contexto, a mediação do professor torna-se muito importante para desmistificar e problematizar os conceitos e sentidos presentes nos livros. Silva, B. (2009, p. 34) frisa que "nesse processo de interação entre leitor e texto, cabe ao professor [...] ouvir seus alunos, sistematizar as ideias geradas e levar os leitores a perceberem outras 
significações que não haviam percebido inicialmente". É interessante também que o professor sempre analise os materiais que estão disponíveis para o seu uso em sala de aula, percebendo e explicitando, de maneira adequada aos propósitos da EA crítica, as concepções que os mesmos carregam.

\section{Referências}

BONOTTO, Dalva Maria B.; SEMPREBONE, Angela. Educação ambiental e educação em valores em livros didáticos de ciências naturais. Ciência \& Educação, v. 16, n. 1, p. 131-148, 2010.

CARVALHO, Isabel Cristina de Moura. Educação ambiental crítica: nomes e endereçamentos da educação. In: LAYRARGUES, Philippe Pomier (Coord.). Identidades da educaşão ambiental brasileira. Brasília: Ministério do Meio Ambiente, 2004.

. Educaşão ambiental: a formação do sujeito ecológico. 3. ed. São Paulo: Cortez, 2008.

CARVALHO, Luiz Marcelo et al. Conceitos, valores e participação política. In: TRAJBER, Rachel; MANZOCHI, Lúcia Helena (Org). Avaliando a Educação Ambiental no Brasil: Materiais Impressos. São Paulo: Gaia, 1996.

A temática ambiental e o processo educativo: dimensões e abordagens. In: CINQUETTI, Heloísa Chalmers Sisla; LOGAREZZI, Amadeu (Org.) Consumo e resíduo: fundamentos para o trabalho educativo. São Carlos: EdUFSCar, 2006.

COELHO, Nelly Novaes; SANTANA, Juliana S. Loyola. A educação ambiental na literatura infantil como formadora de consciência de mundo. In: TRAJBER, Rachel; MANZOCHI, Lúcia Helena (Org). Avaliando a Educação Ambiental no Brasil: Materiais Impressos. São Paulo: Gaia, 1996.

COSTA, Daniel Monteiro. Catando piolbos, contando histórias. São Paulo: Brinque-Book, 2006. 
GONZÁLEZ GAUDIANO, Edgar. Educação ambiental para a biodiversidade: conceitos e práticas. In: JUNQUEIRA, Viviane; NEIMAN, Zysman (Org). Educação ambiental e conservação da biodiversidade: reflexões e experiências. Barueri: Manole, 2007.

GUIMARÃES, Mauro. Educação ambiental crítica. In: LAYRARGUES, Philippe Pomier (Coord.). Identidades da educação ambiental brasileira. Brasília: Ministério do Meio Ambiente, 2004.

KIEFER, Charles. Você viu meu pai por aí?. Rio de Janeiro: Civilização Brasileira, 2007.

LAYRARGUES, Philippe Pomier (Coord.). Identidades da educação ambiental brasileira. Brasília: Ministério do Meio Ambiente, 2004.

LOUREIRO, Carlos Frederico Bernardo. Educação ambiental transformadora. In: LAYRARGUES, Philippe Pomier (Coord.). Identidades da educação ambiental brasileira. Brasília: Ministério do Meio Ambiente, 2004.

MARPICA, Natália Salan. As questões ambientais nos livros didáticos de diferentes disciplinas da quinta-série do Ensino fundamental. 2008. 169 f. Dissertação (Mestrado em Educação) - Universidade Federal de São Carlos, São Carlos, 2008.

MAULIN, Gilfredo Carrasco. O conhecimento intercultural: um diálogo com a educação ambiental. Revista Brasileira de Educação Ambiental, Cuiabá, n. 4, p. 60-65, jul. 2009.

MELO, Elizabete Amorim de Almeida. Livros paradidáticos de língua portuguesa para crianças: uma fórmula editorial para o universo escolar. 2004. $140 \mathrm{f}$. Dissertação (Mestrado em Educação) - Faculdade de Educação, Universidade Estadual de Campinas, Campinas, 2004.

MORAES, Roque. Uma tempestade de luz: a compreensão possibilitada pela análise textual discursiva. Ciência \&o Educação, v. 9, n. 2, p. 191-211, 2003.

MORAES, Roque; GALIAZZI, Maria do Carmo. Análise textual discursiva: processo reconstrutivo de múltiplas faces. Ciência \& Educação, v. 12, n. 1, 2006, p. 117-128.

MORAES, Roque; GALIAZZI, Maria do Carmo..Análise Textual Discursiva. Ijuí: Ed. Unijuí, 2007. 
OLIVEIRA JÚNIOR, Geraldo Coelho de. Aculturação indígena: uma introdução histórica. Revista Humanidades, , n. 1, out./dez. 2003.

SAUVÉ, Lucie. Uma cartografia das correntes em educação ambiental. Trad. Ernani Rosa. In: SATO, Michèle; CARVALHO, Isabel Cristina de Moura (Org). Educação Ambiental: pesquisa e desafios. Porto Alegre: Artmed, 2005.

- Educação ambiental: possibilidades e limitações. Educação e Pesquisa. São Paulo, v. 31, n. 2, maio/ago., 2005b.

SILVA, Bruna Lidiane Marques da. Programa Nacional Biblioteca da Escola edição 2006: a chegada dos acervos na rede Municipal de Ensino de Belo Horizonte e a leitura de obras por jovens leitores. 2009. 144 f. Dissertação (Mestrado) - Faculdade de Educação, Universidade Federal de Minas Gerais. Belo Horizonte, 2009.

SILVA, Rosana Louro Ferreira. O meio ambiente por trás da tela: estudo das concepções de Educação Ambiental dos filmes da TV Escola. Tese (Doutorado) - Faculdade de Educação, Universidade de São Paulo,.São Paulo, 2007.

- Ciência e Tecnologia em programas educativos de meio ambiente. Enseñanza de las Ciencias, v. extra, p. 1138-1142, 2009.

TOZONI-REIS, Marília Freitas de Campos. Educação ambiental: natureza, razão e história. Campinas: Autores Associados, 2004.

VIEZZER, Moema. A educação ambiental na ótica das novas relações sociais de gênero. In: SORRENTINO, Marcos; TRAJBER, Rachel; BRAGA, Tania (Org.). Cadernos do III fórum de educação ambiental. São Paulo: Gaia, 1995.

VIEZZER, Moema; RODRIGUES, Carmen Lúcia; MOREIRA, Tereza. Relações de gênero na educação ambiental. In: TRAJBER, Rachel; MANZOCHI, Lúcia Helena (Org.). Avaliando a Educação Ambiental no Brasil: Materiais Impressos. São Paulo: Gaia, 1996.

WALTY, Ivete. Literatura e escola: anti-lições. In: EVANGELISTA, Aracy Alves; BRANDÃO, Heliana Maria; MACHADO, Maria Zélia. A escolarização da leitura literária: o jogo do livro infantil e juvenil. 2. ed. Belo Horizonte: Autêntica, 2003.

ZILBERMAN, Regina. Literatura infantil e ensino. São Paulo: Cortez, 1990. 
ZOTZ, Werner. Barco branco em mar azul. 17 ed. Florianópolis: Letras Brasileiras, 2005.

Artigo: recebido em 18/08/2010 - aprovado em 22/12/2010 